\title{
Dominik Klimke
}

\section{Die Vertragsübernahme}

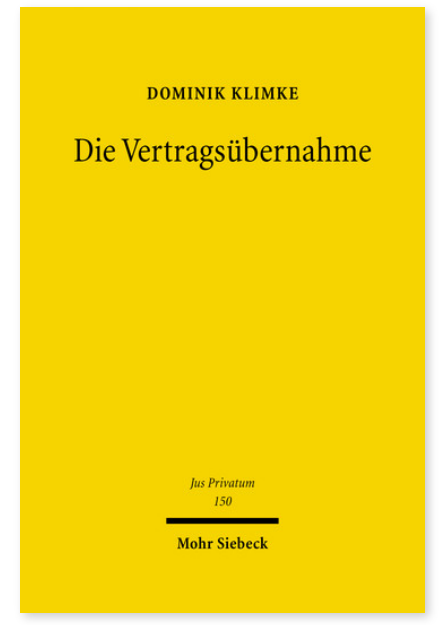

2010. XXVI, 433 Seiten. JusPriv 150

ISBN 978-3-16-151227-8

DOI 10.1628/978-3-16-151227-8

eBook PDF 119,00€

ISBN 978-3-16-150154-8

Leinen $119,00 €$
Vertragsübernahmen, d.h. die Auswechslung eines Vertragspartners durch Rechtsgeschäft, kommen in der Praxis, zum Beispiel bei Miet- und Darlehensverträgen, häufig vor. Dominik Klimke analysiert und systematisiert die komplexen rechtlichen Beziehungen der Beteiligten: Welcher Abschlussmechanismus steht den Parteien zur Verfügung (dreiseitiger Vertrag oder zweiseitige Übernahmevereinbarung mit Zustimmung des dritten Betroffenen)? Welche Ansprüche und Rechte bzw. Verpflichtungen werden von der Übernahme erfasst? Gibt es ein Grundgeschäft und wie ist dieses gegebenenfalls zu qualifizieren? Sind verbraucherschützende Normen, die unmittelbar nur für den Neuabschluss gelten, auch auf die Vertragsübernahme anzuwenden? Welche Folgen haben Defekte im Verhältnis zwischen zwei Parteien für den Dritten? Wie wirkt sich die Übernahme prozessual aus? Bei der Beantwortung dieser Fragen kommt der Autor zu differenzierten und zum Teil neuen Lösungen.

Dominik Klimke Geboren 1969; Studium der Rechtswissenschaft in Bonn und Berlin; 2003 Promotion; 2009 Habilitation; derzeit Privatdozent an der Freien Universität Berlin.

\section{Jetzt bestellen:}

https://mohrsiebeck.com/buch/die-vertragsuebernahme-9783161512278?no_cache=1

order@mohrsiebeck.com

Telefon: +49 (0)7071-923-17

Telefax: $+49(0) 7071-51104$ 